\title{
Anatomical and clinical correlates of the precondylar tubercle
}

\author{
JAFFAR, A. A. * \\ Department of Basic Medical Sciences, College of Medicine, University of Sharjah, \\ United Arab Emirates, PO Box 45521, Sharjah, United Arab Emirates \\ ${ }^{*}$ E-mail: akramjfr@gmail.com
}

\begin{abstract}
Introduction: The possible presence of the precondylar tubercle should be considered in order to avoid misinterpretation in radiographic images and confusion during surgical intervention. This study is aimed to describe and report the frequency of the precondylar tubercle and similar variations at the anterior margin of foramen magnum in order to alert the clinical community of their presence and of the possible associated variations. Materials and Methods: Fifty dry skulls were examined for variations at the anterior margin of foramen magnum. One skull with bilaterally prominent precondylar tubercles was studied using a spiral computerized tomography in order to demonstrate the radiographic appearance of the tubercle. Results: Precondylar tubercles were observed in $10 \%$ of the skulls. Other simulating observations included the presence of a midline spur, bilateral depression anteromedial to the occipital condyles, third occipital condyle, and a partly divided occipital condyle. In $89 \%$ of the cases these variations were associated with septation of the hypoglossal canal. Conclusion: The presence of a mere precondylar tubercle is not expected to produce neurological manifestations. However, its possible association with other variations should be considered. The size and location of the precondylar tubercle might evade plain radiographic films, but it can be readily revealed in axial computerized tomograms.
\end{abstract}

Keywords: anatomical variations, osteology, precondylar tubercle, craniovertebral junction.

\section{Introduction}

The precondylar tubercle (also known as the basilar, mamillar or papillar process) is a small occasional tubercle located immediately anterior to the occipital condyle. When present, the precondylar tubercle replaces the small depression that usually provides attachment for rectus capitis anterior muscle (BERGMAN, AFIFI and MIYAUCHI, 2013; LIEBERMAN, 2005). A centrally placed tubercle has been regarded as two fused tubercles (BERRY and BERRY, 1967).

The precondylar tubercle has been described in anthropology literature as a skeletal variant in Oceanic crania (MARSHALL, 1955); crania of American-Whites and -Negroes (McDONNELL and HARRISON, 1996); Burmese and old Egyptian crania (BERRY and BERRY, 1967); Midwest-Kyushuites (Japan) crania (HOJO, 1980); crania of Uttar Pradesh (India) (GUPTA, SRIVASTAVA, GUPTA et al., 1981); and Mexican crania (BEEKMAN and CHRISTENSEN, 2003).

The precondylar tubercle has been included as one of the non-metrical human cranial traits for the estimation of race from skeletal data (BERRY and BERRY, 1967; BERRY, 1975; HAUSER and DE STEFANO, 1989). Non-metric traits are skeletal manifestations such as additional sutures, facets, bony processes, canals and foramina, which occur in a minority of skeletons and were thought to suggest familial affiliations. Some non-metric traits are believed to be occupational stress markers, rather than phenotypic. This is because human bone is plastic and responds to muscle development by functional pressures (HOLST, 2005).

Developmental events at the craniovertebral junction can help in our understanding of the etiology of related variations. The region around foramen magnum is developmentally derived from three major sources: the occipital sclerotomes, parachordal plate, and the first cervical sclerotome. The occipital sclerotomes fuse with a fenestration remaining parasagittally to form the hypoglossal canal. The occipital sclerotomes are assimilated into the region of the caudal parachordal plate to form the basioccipital region and contribute to the anterior margin of foramen magnum. The caudal portion of the parachordal plate (referred to as exoccipital) extends laterally and dorsally. Laterally, it joins the occipital somites to form the lateral margins of the foramen magnum. The occipital condyles in part are derived from the exoccipital as well as from the rostral segment of the first cervical somite. Dorsally, the exoccipital extends to contribute to the posterior margin of the foramen magnum. The first cervical sclerotome is divided into a cranial and a caudal segment. The cranial half contributes to the occipital condyles, apical odontoid ligament, and the tip of the odontoid process. The caudal portion gives origin to the lateral masses, anterior and posterior arches of the first cervical vertebra. The second cervical sclerotome forms the axis (CAHAN, MALKASIAN and BENTSON, 1987).

Abnormalities of the craniovertebral junction, in addition to those associated with the occipital bone are also associated with the atlas (NAYAK, VOLLALA and RAGHUNATHAN, 2005; JAYANTHI, KULKARNI and KULKARNI, 2003) and the axis (RAO, 2002; KOTIL and KALAYCI, 2005). They are of interest to anatomists and to clinicians because they may produce clinical symptoms.

The progress in neuroimaging techniques has increased interest in aggressive craniovertebral surgery. Such surgery 
requires knowledge of anatomical aspects and possible variations of the craniovertebral junction. In cases of ventral irreducible compression of the cervicomedullary junction, precise anatomy of the caudal part of the clivus and anterior rim of foramen magnum is of considerable importance to neurosurgeons using the transoral approaches to the clivus (MENEZES, 1996) as well as the alternative anterolateral cervical approach to the craniovertebral junction (McDONNELL and HARRISON, 1996).

Abnormalities of the occipital bone, foramen magnum, or first two cervical vertebrae that decrease the potential space for the lower brain stem and cervical cord can result in cerebellar, lower cranial nerve, and spinal cord symptoms. The third occipital condyle is reported to produce a marked stenosis of the spinal canal at the level of the Atlas with cord compression and evidence of myelopathy (KOTIL and KALAYCI, 2005).

This study aims to report variations at the anterior margin of foramen magnum with a special emphasis on the precondylar tubercle in order to alert the clinical community of their presence and of the possible associated variations.

Materials and Methods

The region around the foramen magnum is situated in the deepest part of the neck making it very difficult to dissect in anatomical dissection practice. From this point of view there is good reason for a study to be done in dry skull material.

Fifty dry adult skulls of Caucasoid origin regardless of gender were examined for variations at the anterior margin of foramen magnum. The skulls were derived from the skeleton inventory of teaching material.

Variations at the anterior margin of foramen magnum were observed. The presence of a bony septum or duplication of the hypoglossal canal, as well as the presence of variations in the occipital condyle was recorded.

In order to demonstrate the radiographic appearance of the precondylar tubercle, one skull with bilaterally prominent precondylar tubercle was scanned using a Toshiba dual slice spiral computerized tomography (CT) scan. Axial slices, $0.5 \mathrm{~mm}$ thick with $20^{\circ}$ angulation were produced at a radiation dose of $120 \mathrm{Kv}$. In order to minimize the bone/air artifact should the CT be done for an empty dry skull, paraffin (Papraplast tissue embedding media, Monojet
Scientific, melting point $57^{\circ}$ ) was used to encapsulate the region around foramen magnum from the inside and outside of the skull (DICKINSON, 2005).

\section{Results}

The precondylar tubercle was observed in 5 out of the 50 skulls examined (10\%). Of these five skulls, one was with a centrally placed precondylar tubercle (Figure la); and one with a well developed unilateral tubercle located on the left side (Figure lb). In the remaining three skulls, the precondylar tubercles were bilateral. Of the latter, one was well-developed and associated on both sides with a depression in the region between the tubercle and the occipital condyle (Figure 1c). Figure 2 shows the appearance of the bilateral precondylar tubercles illustrated in Figure lc in serial axial CT slices.

Other observations at the anterior margin of foramen magnum that might mimic a precondylar tubercle included one skull with a midline spur at the anterior margin of foramen magnum. Another skull showed a bilateral depression anteromedial to the occipital condyles similar to that shown in Figure lc but without a precondylar tubercle; the depression was associated with thickening of the anterior margin of foramen magnum (Figure 3a). Finally, a third occipital condyle was observed in two skulls (4\%). Each third occipital condyle had a clear smooth articular facet. One such third occipital condyle was well-developed and was associated with the presence of a transverse ridge on the articular surface of the "proper" occipital condyles, partially dividing the "proper" condyle into two parts (Figure $3 \mathrm{~b}$ ). The less-developed third occipital condyle was on the other hand associated with a well-developed median spur (Figure 3c).

In eight of the above nine cases (89\%), the bony variation at the anterior margin of foramen magnum was associated with a unilateral or bilateral variation of the hypoglossal canal including a complete or incomplete septum and multiple canals. The skull with unilateral precondylar tubercle was the only one which did not show any variation in the hypoglossal canal. A bipartite hypoglossal canal (unilateral or bilateral) was otherwise observed in $12(24 \%)$ of the skulls examined;
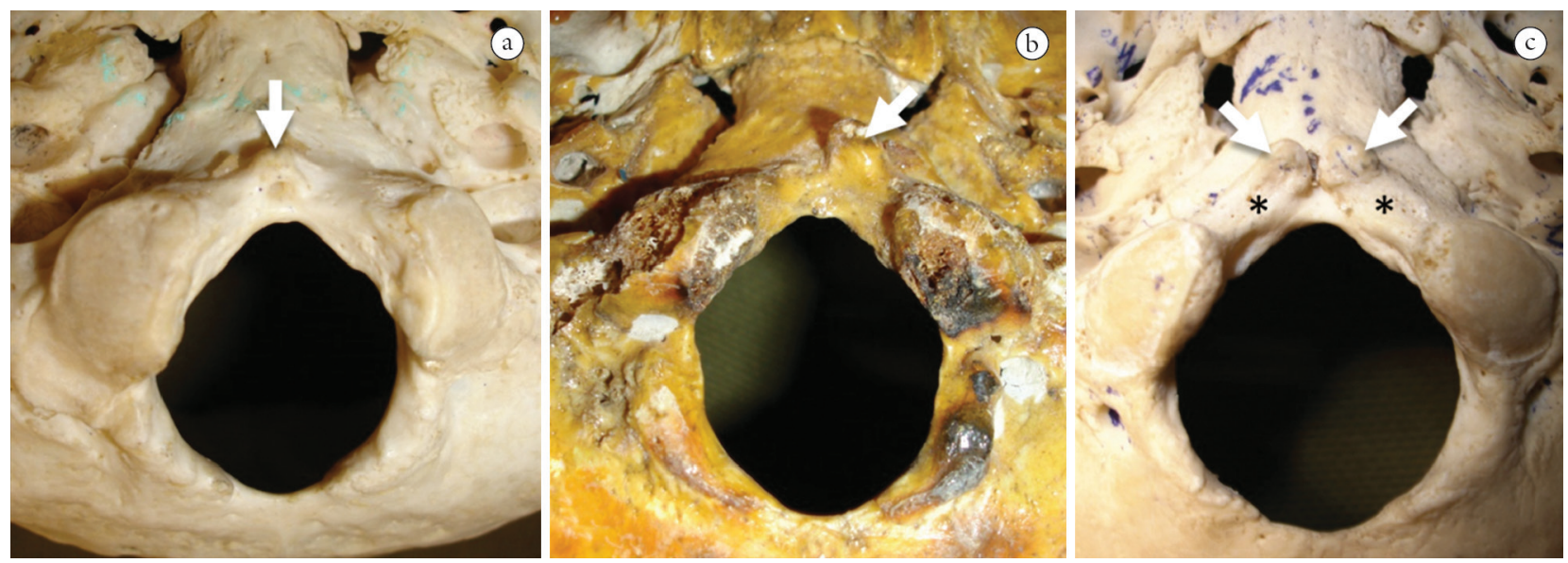

Figure 1. Types of precondylar tubercle (arrow). (a) central, (b) unilateral, (c) bilateral precondylar tubercles with a depression (asterisk) in the region between each tubercle and the occipital condyle. 
in only four instances (25\%) it was not associated with accompanying variation around foramen magnum.

\section{Conclusions}

\subsection{Anatomical correlates}

The $10 \%$ incidence of precondylar tubercle which was reported in this study fits well among most studies which reported incidence rates ranging from 0\% (BEEKMAN and CHRISTENSEN, 2003) to 20\% (BROMAN, 1957; BERRY, 1975; VASUDEVA and CHOUDHRY, 1996; BARTELS, 1998; KALE, OZTURK, AKSU et al., 2009). The high incidence rate of $36.5 \%$ which was once reported (HOJO, 1980) includes the presence of very small structures which are not amenable to our descriptions or those reported by others (BERRY and BERRY, 1967; BERGMAN, AFIFI and MIYAUCHI, 2013; LIEBERMAN, 2005). Most of the precondylar tubercles that were observed in this study $(80 \%)$ were accompanied by a bipartite hypoglossal canal.

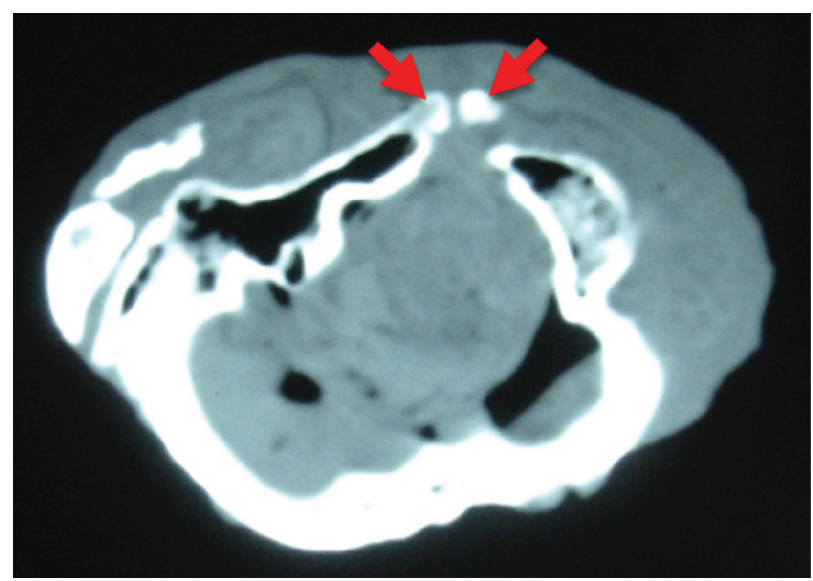

Figure 2. Axial CT slice at the base of a dried skull (same as in Figure 1c) with well-developed bilateral precondylar tubercles (arrows). Note the shadow of the encapsulating paraffin wax.
Although this study did not take gender and age into consideration regarding the incidence of the precondylar tubercle, no such association was reported by in one study (BERRY, 1975). However, the results of other studies in this respect are conflicting: some reported higher incidence in males (BARTELS, 1998; HOLST, 2005) while others reported higher incidence in females (VASUDEVA and CHOUDHRY, 1996).

The incidence of the third occipital condyle, which was found to be $4 \%$ in this study, is reported by others to range from $0.5 \%$ to $3 \%$ (VON LUDINGHAUSEN, PRESCHER, KAGEYA et al., 2006; KALE, OZTURK, AKSU et al., 2009; BERGMAN, AFIFI and MIYAUCHI, 2013). The third occipital condyle reported in two skulls in this study was not a solitary variation but associated with two of the following variations: midline spur, septation of the hypoglossal canal and a transverse ridge on the articular surface of the "proper" occipital condyles. A case of a third occipital condyle has also been reported to be associated with duplication of both occipital condyles and a bony septation of both hypoglossal canals (TUBBS, SALTER and OAKES, 2005).

A partly divided occipital condyle has also been described (BERGMAN, AFIFI, and MIYAUCHI, 2013). Its incidence has been reported to be $0.8 \%$ (NADERI, KORMAN, CITAK et al., 2005). In this study it was observed in one of the examined skulls $(2 \%)$ where it was associated with a third occipital condyle and a bipartite hypoglossal canal.

The spur at the anterior margin of foramen magnum has been attributed to ossification of the ligament of the odontoid process (BERGMAN, AFIFI and MIYAUCHI, 2013). However, its association with a septate hypoglossal canal in the two cases observed in this study together with a third occipital condyle in one of them should attract attention to an embryological factor behind its formation.

A bipartite hypoglossal canal was observed in $24 \%$ of the skulls examined in this study. The presence of such a canal may be understood when the posterior part of the skull that develops around the notochord is considered to be basically comparable to one or more vertebrae (O'RAHILLY, MÜLLER and MYER, 1983). Thus the occipital bone
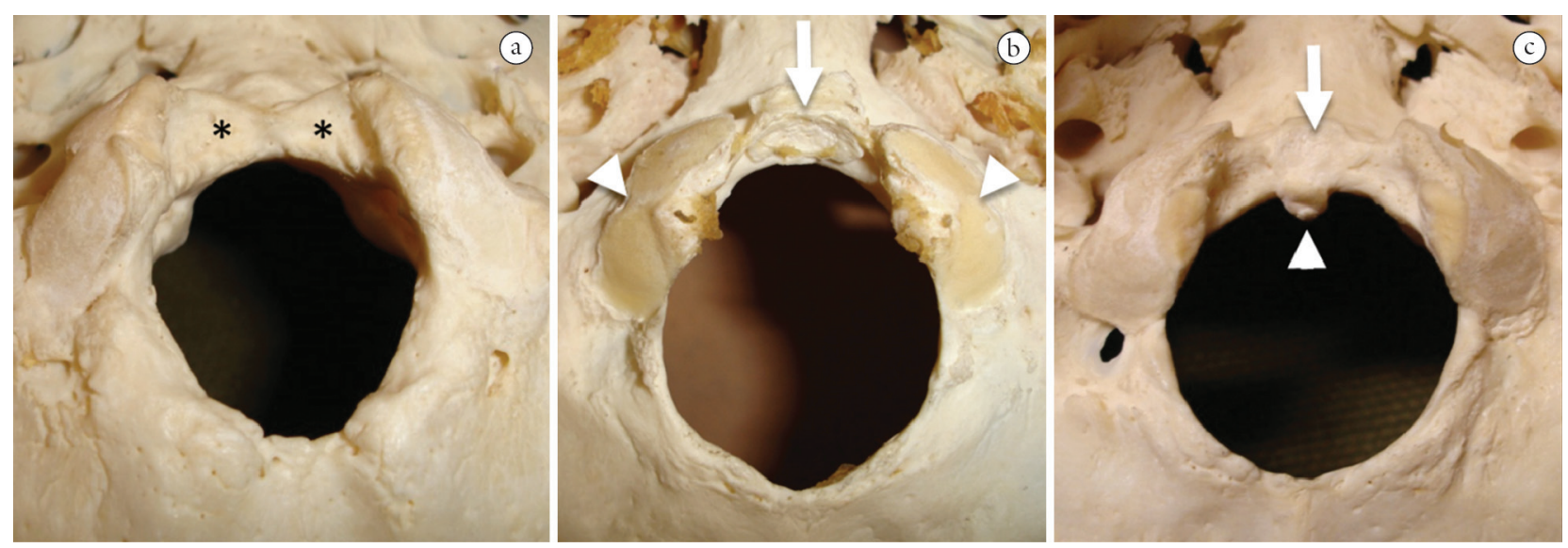

Figure 3. Variations at the anterior margin of foramen magnum. (a) bilateral depression (asterisk) anteromedial to the occipital condyles with thickening of the anterior margin of foramen magnum. (b): third occipital condyle (arrow) with a clear smooth articular facet associated with the presence of a transverse ridge at the articular surface of the occipital condyles (arrow heads). (c) third occipital condyle (arrow) associated with a well-developed median spur (arrow head). 
is formed by the fusion of the sclerotomes corresponding to the roots of the hypoglossal nerve (O'RAHILLY and MÜLLER, 1984).

\subsection{Clinical correlates}

Variations at the craniovertebral junction are expected to associate one another from the embryological point of view (O'RAHILLY, MÜLLER and MYER, 1983; CAHAN, MALKASIAN, and BENTSON, 1987). Such association has been reported (TUBBS, SALTER and OAKES, 2005) and was observed in this study particularly in the septation of the hypoglossal canal which was associated in $75 \%$ of the cases with a variation at the anterior margin of foramen magnum.

From the anatomical point of view, the location of a mere precondylar tubercle is not expected to produce neurological manifestations resulting from compression of the spinal cord or the caudal part of the medulla oblongata since it is located outside the circumference of foramen magnum. However, its association with other variations dictated by the embryological events should be considered as clinically significant.

The size and location of the precondylar tubercle might evade plain radiographic films unlike other entities such as a third occipital condyle. However with the advancement of the imaging techniques and the extensive use of CT and MRI, it would be expected that precondylar tubercles will be more frequently reported in clinical literature. The CT images put foreword in this study should increase the awareness of their shape and location and attract the attention to their presence for differential diagnosis.

Recognition of these structures and associated variations help in distinguishing variants from abnormal structures during computed tomography examinations, and in avoiding misinterpretations that lead to confusion during surgical intervention.

\section{References}

BARTELS, NG. A test of non-metrical analysis as applied to the "Beaker Problem". Edmonton, Alberta: Department of Anthropology, University of Alberta, 1998. 136 p. [Master's Thesis].

BEEKMAN, CS and CHRISTENSEN, AF. Controlling for doubt and uncertainty through multiple lines of evidence: A new look at the Mesoamerican Nahua migrations. Journal of Archaeological Method and Theory, 2003, vol. 10, n. 2, p. 111-164. http://dx.doi. org/10.1023/A:1024519712257

BERGMAN, AR., AFIFI, AK. and MIYAUCHI, R. Occipital bone. In Illustrated Encyclopedia of Human Anatomic Variation: Opus V: Skeletal Systems: Cranium. Available from <http://www. anatomyatlases.org/AnatomicVariants/SkeletalSystem/Text/ OccipitalBone.shtml>. Available from: 30/05/2013.

BERRY, AC and BERRY, RJ. Epigenetic variation in the human cranium. Journal of Anatomy, 1967, vol. 101, Pt 2, p. 361-379. PMid:4227311 PMCid:PMC1270890

BERRY, AC. Factors affecting the incidence of non-metrical skeletal variants. Journal of Anatomy, 1975, vol. 120, Pt 3, p. 519-535. PMid:129447 PMCid:PMC1231693

BROMAN, GE. Precondylar tubercles in American Whites and Negroes. American Journal of Physical Anthropology, vol. 15, n. 1, p. 125-135, 1957. PMid:13424675. http://dx.doi.org/10.1002/ ajpa.1330150114
CAHAN, LD., MALKASIAN, DR. and BENTSON, JR. Craniocervical bone malformations. In VINKEN, PJ., BRUYN GW. and KLAWANS, HL. (Eds.). Handbook of clinical neurology. Amsterdam: Elsevier, 1987. p. 384-386. Vol. 50.

DICKINSON, P. Neuroimaging. In Anmual Veterinary Neurology Symposium, 2005. Davis, USA: University of Californi, 2005. [Resumos]. Available from: <http://www.ivis.org/proceedings/ neuroucdavis/2005/dickinson3.pdf>. Access in: 15/07/2013.

GUPTA, SC., SRIVASTAVA, AK., GUPTA, CD. and ARORA, AK. Incidence of precondylar tubercle in crania of Uttar Pradesh. Anthropologischer Anzeiger, 1981, vol. 39, n. 4, p. 321-325.

HAUSER, G. and DE STEFANO, GF. Epigenetic variants of the human skull. Stuttgart: Schweizerbart, 1989. p. 134-136.

HOJO, T. Precondylar tubercle and anteromedian marginal process around the foramen magnum in modern Midwest-Kyushuites. Journal of University of Occupational and Environmental Health, 1980 , vol. 2 , n. 3, p. $309-313$

HOLST, M. Analysis of non-metric traits. In SPALL, CA. and TOOP, NJ. (Eds.). Blue Bridge Lane \& Fishergate House, York. Report on Excavations: July 2000 to July 2002. Archaeological Planning Consultancy Ltd., 2005. Available from: <http://www. archaeologicalplanningconsultancy.co.uk/mono/001/rep_bone_ hum2h.html>. Access in: 1/6/2013.

JAYANTHI, V., KULKARNI R. and KULKARNI RN. Atlantooccipital fusion - report of two cases. Journal of the Anatomical Society of India, 2003, vol. 52, n. 1, p. 71-73.

KALE, A., OZTURK, A., AKSU, F., GURSES, I., GAYRETLI, O., BAYRAKTAR, B., ZEYBEK, F., TASKARA, N., ARI, Z., and SAHINOGLU, K. Bony variations of the craniovertebral region. Neurosciences, 2009, vol. 14, n. 3, p. 296-297. PMid:21048637

KOTIL, K. and KALAYCI, M. Ventral cervicomedullary junction compression secondary to condylus occipitalis (median occipital condyle), a rare entity. Journal of Spinal Disorders and Technique, 2005, vol. 18 , n. 4 , p. 382-384. PMid:16021022. http://dx.doi. org/10.1097/01.bsd.0000166639.23448.32.

LIEBERMAN, DE. Head and neck. In STANDRING, S. (Ed.). Gray's anatomy, the anatomical basis of clinical practice. 39th ed. Edinburgh: Elsevier Churchill Livingstone, 2005. p. 464.

MARSHALL, DS. Precondylar tubercle incidence rates. American Journal of Physical Anthropology, 1955, vol. 13, n. 1, p. 147-151. PMid:14361664. http://dx.doi.org/10.1002/ajpa.1330130112.

McDONNELL, DE. and HARRISON, SJ. Anterolateral cervical approach to the craniovertebral junction. In: WILKINS, RH. and RENGACHARY, SS. (Eds.). Neurosurgery. 2nd ed. New York: McGraw Hill, 1996. p. 1641-1653. Vol. 2.

MENEZES, AH. Transoral approaches to the clivus and upper cervical spine. In: WILKINS, RH. and RENGACHARY, SS. (Eds.). Neurosurgery. 2nd ed. New York: McGraw Hill, 1996. p. 16291639. Vol. 2 .

NADERI, S., KORMAN, E., CITAK, G., GUVENCER, M., ARMAN, C., SENOGLU, M., TETIK, S., and ARDA, M. Morphometric analysis of human occipital condyle. Clinical Neurology and Neurosurgery, 2005, vol. 107, n. 3, p. 191199. PMid:15823674. http://dx.doi.org/10.1016/j. clineuro.2004.07.014

NAYAK, S., VOLLALA, V. and RAGHUNATHAN, D. Total fusion of atlas with occipital bone: a case report. Neuroanatomy, 2005 , vol. 4 , p. 39-40.

O'RAHILLY, R. and MÜLLER, F. The early development of the hypoglossal nerve and occipital somites in staged human embryos. American Journal of Anatomy, 1984, vol. 169, n. 3, p. 237-257. PMid:6720613. http://dx.doi.org/10.1002/aja.1001690302. 
O'RAHILly, R., MÜlLER, F., and MYER, D. The human vertebral column at the end of the embryonic period proper 2.The occipitocervical region. Journal of Anatomy, 1983, vol. 136, Pt 1, p. 181-195. PMid:6833119 PMCid:PMC1171939

RAO, P. Median (third) occipital condyle. Clinical Anatomy, 2002, vol. 15, n. 2, p. 148-151. PMid:11877795. http://dx.doi. org/10.1002/ca.1111.

TUBBS, RS., SALTER, EG. and OAKES, WJ. Duplication of the occipital condyles. Clinical Anatomy, 2005, vol. 18, n. 2, p. 92 95. PMid:15696520. http://dx.doi.org/10.1002/ca.20073.
VASUDEVA, N. and CHOUDHRY, R. Precondylar tubercles on the basiocciput of adult human skulls. Journal of Anatomy, 1996, vol. 188, Pt 1, p. 207-210. PMid:8655408 PMCid:PMC1167648.

VON LUDINGHAUSEN, M., PRESCHER, A., KAGEYA, I. and YOSHIMURA, K. The median atlanto-occipital joint in advanced age. Spine, 2006, vol. 31, n. 14, p. E430-436. PMid:16778671. http://dx.doi.org/10.1097/01.brs.0000222156.96731.34.
Received Oct 5, 2013 Accepted Sept. 18, 2014 